\title{
Moroccan Obese Patients with or without Metabolic Syndrome: Dietary Pattern and Risk of Cardiovascular Disease
}

\author{
Najwa Benalioua ${ }^{1}, \operatorname{Karima}_{\text {Mohtadi }}{ }^{1}$, Rajaa Msaad ${ }^{1}$, Rajaa Essadik $^{1}$, Halima Lebrazi $^{1}$, Anass $\operatorname{Kettani}^{1}$, \\ Hassan Taki ${ }^{1}$, Rachid Saïle ${ }^{* 1}$ \\ ${ }^{1}$ Laboratory of biology and health, URAC 34, Faculty of sciences Ben Msik, Hassan II University of Casablanca, Morocco
}

Received: January 12, 2018; Accepted: February 02, 2018; Published: February 28, 2018

*Corresponding author: SAILE Rachid, Professor, Laboratory of Biology and Health, URAC 34, Hassan II University of Casablanca, Faculty of Sciences Ben M'Sik, Avenue Cdt Driss El Harti, B.P 7955, Sidi Othman, Casablanca, Morocco, Tel: (+212) 661218525 , fax: (+212) 522704675 , E-mail : sailerachid@yahoo.fr

\section{Abstract}

Introduction: Metabolic syndrome (MetS) is a cluster of risk factors for Cardiovascular Diseases (CVD) that includes central obesity, hypertension, glucose intolerance, high triglyceride, and low high-density lipoprotein cholesterol. Its prevalence is rapidly increasing worldwide. This study aimed to identify dietary patterns in Moroccan obese patients with or without metabolic syndrome and its association to CVD.
\end{abstract}

Patients \& methods: Study concerned 241 obese patients, meanage $53.27 \pm 9.66$ years, with or without metabolic syndrome. The data included anthropometric measurements, a $24 \mathrm{H}$ nutritional recall, food frequency intake, lipoprotein and apolipoproteins profiles and several lipid ratios.

Results: Obese patients with MetS, presented higher body mass index, waist circumference, systolic and diastolic blood pressures values than patients without MetS. 17.02\%, 31.92\%, 33.19\%, 13.62\% and $4.26 \%$ of the studied population had one, two, three, four and five MetS components, respectively. The most prevalent MetS components were high waist circumference, hypertension and diabetes while low HDL-C was the least one in both groups. The ratio of TC/HDL and atherogenic index of plasma were the best predictors of MetS and their odd ratios were significantly higher in men than in women. We reported also several lipoprotein alterations in both groups. Furthermore, obese patients with MetS diet was more caloric very rich in saturated fatty acids but poorer in polyunsaturated fatty acids and monounsaturated fatty acids, in vitamins B9 and E. Both groups consume meals which macronutrient compositions were similar, typical Moroccan dishes. The consumption of Retinol, Beta-carotene, Vitamin $\mathrm{C}$ and trace elements was significantly higher in obese patients with MetS than in those without, whereas consumption of cholesterol and fibers were not significantly different. Conclusion: Our study shows that Moroccan obese patients with a hypercaloric diet and unbalanced fatty acids intakes, present disturbance in lipoprotein profile, with 3 to 5 components of MetS. All these parameters and disturbance may contribute to the development of CVD. The burden of CVD poses a serious public health problem in the region. It is strongly associated with dietary pattern.

Keywords: Nutrition, obese patients, metabolic syndrome, cardiovascular diseases.

\section{Introduction}

Cardiovascular Diseases (CVD) still currently progress, remaining the first cause of morbidity and mortality in the world. In the worldwide ladder and cause more than 15 million each year, according to the World Health Organization (WHO; Geneva) $[1,3,4]$. Accounting for 17.3 million deaths per year, a number that is expected to grow to more than 23.6 million by 2030 [5]. The increase of the incidence of these diseases has its origins in exposition to physiological and behavioral risk factors and the old aged population. Epidemiological and clinical studies have clearly established multifactorial origins of CVD and determined two kinds of Cardiovascular Risk Factors (CVRF): non variable ones (age, sex, familial history,...) and variable ones (hypertension, diabetes, dyslipidemia, tabagism, unhealthy diet, sedentarity, psychosocial factors, ...) [1].

In 2008, cardiovascular deaths represented 30 percent of all global deaths, with 80 percent of those deaths taking place in low- and middle-income countries [6].

In Morocco, as in most developing countries, CVD were responsible for $30.4 \%$ mortality and it's a first cause of mortality. Thus, CVD is today the largest single contributor to global mortality and will continue to dominate mortality trends in the future $[6,7]$.

A major factor of the increasing prevalence of CVD worldwide is the on-going nutrition transition with progressive shifts to a westernized diet high in saturated fats and sugar, and a more sedentary lifestyle urbanization and globalization are fuelling the nutrition transition. These changes result in rapidly increasing levels of obesity, type 2 diabetes, dyslipidemia and hypertension, collectively known as the metabolic syndrome, which increase the risk of developing cardiovascular diseases [8, 9]. Furthermore, in recent decades the increased occurrence of CVD is not only attributed to changed dietary habits but also a reduced physical activity [5].

Even more, there is no standard of care for treating the 
metabolic syndrome since the prevalence of individual disorders varies by population and there is no common link between all metabolic abnormalities included. For example, the main predictor of metabolic syndrome among French populations is hypertension, whereas among US populations the main predictor is HDL cholesterol [10-12].

In Morocco, a developing country that is also experiencing demographic and health and nutritional transitions, few epidemiological studies have been conducted to characterize the magnitude of the prevalence of metabolic syndrome and risk of cardiovascular disease, as the country is still mostly focused on the problems associated with poor health and under nutrition in large segments of the population.

This study aimed to identify dietary patterns in Moroccan obese with or without metabolic syndrome and its association to cardiovascular diseases.

\section{Methods}

The study was performed on a total of 241 obese patients which 183 women and 60 men, mean age 53, 27 \pm 9.66 years, with or without MetS.

In these patients, metabolic syndrome was defined as the presence of at least 3 of the 5 components described by the National Cholesterol Education Program Adult Treatment Panel III (NCEP ATP III):

- Waist circumference $>102 \mathrm{~cm}$ for men and $>88 \mathrm{~cm}$ for women;

- Fasting plasma TG level $\geq 150 \mathrm{mg} / \mathrm{dl}$;

- HDL-C HDL-cholesterol level $<50 \mathrm{mg} / \mathrm{dL}$, and a fasting plasma glucose level.110 mg/dL and/or 130/ $85 \mathrm{mmHg}$ systolic and diastolic bloods [13].

At the time of enrolment, the patients completed a health and lifestyle questionnaire indicating socio demographic characteristics, medical history, nutrition (24 recall and food frequency) and lifestyle factors, followed by clinical examination. All participants were Moroccan adult volunteers living in Casablanca and its neighboring areas and all provides their written informed consents. Thus, we excluded from this study all patients having some diseases affecting lipoprotein metabolism.

\section{Anthropometric Measurements and Analysis of Lipid Parameters}

The file analyses consisted on exploitation of Anthropometric parameters was included height, body mass, Waist Circumference (WC) and Systolic (sBP) and Diastolic Blood Pressure (dBP). Even more, the blood pressure was measured on the subject investigated at rest and sit for 5 minutes, three successive measurements, the average blood pressure readings of the last two defining blood pressure reported in this study.

Low-Density Lipoprotein Cholesterol (LDL-C) and Very LowDensity Lipoprotein Cholesterol (VLDL-C) levels were calculated according to the friedwald's formula. Furthermore, we have evaluated Apolipoprotein A1 (Apo1), Apolipoprotein B (Apo B) concentrations using nephelometry techniques. Apolipoproteine ratios, such as Apolipoprotein B to Apolipoprotein A1 (Apo B/ Apo A1), LDL to Apo B (LDL/ApoB) and HDL to Apo A1 (HDL/ Apo A1), were calculated; AIP was defined bas the logarithm of the TG/HDL ratio.

Serum equivalent CRP concentrations $10.0 \mathrm{mg} / \mathrm{L}$ were considered clinically elevated and indicative of current infection.

\section{Statistical Analysis}

The results are presented as mean \pm Standard Deviation (SD). Lipid parameters mean levels and standard deviations were calculated in each group of participants.

The differences in general and clinical characteristics (mean value of the parameters in the recall and the lipid levels) between the with and without MetS groups were with assessed by ANOVA tests.

Linear regression analysis was performed to test associations between lipid ratios and predicted risk of developing a CVD, Myocardial Infarction (MI), stroke and coronary heart disease CHD. Differences with a $P<0.05$ were considered statistically significant.

All analyses were conducted using $\mathrm{R}$ version 2.12 .0 for statistical analysis.

\section{Results}

Baseline characteristics of our study population are summarized in table 1 . Obese patients with MetS presented higher Body Mass Index (BMI), Waist Circumference (WC) Systolic and Diastolic Blood Pressures (sBP and dBP) values than patients without MetS.17.02 \%, $31.92 \%, 33.19 \%, 13.62 \%$ and $4.26 \%$ of the studied population had one, two, three, four and five MetS components respectively. The most prevalent MetS components were high WC, hypertension and diabetes while low HDL-C was the least one in both groups. In addition, the majority of patients had CRP levels upper than $3 \mathrm{mg} / \mathrm{dL}$. Obese participants with MetS showed higher levels of Total Cholesterol (TC), Triglycerides (TG), VLDL-C and Apo B levels as compared to choose without MetS, while LDL-C and Apo A1 were similar between both groups.

The reduction of high density lipoprotein cholesterol (HDL-C), observed in patients with MetS, leads to higher lipid and apolipoproteins ratios such as TG/ HDL. LDL/ ApoB and HDL/ ApoA1 decreased in presence of MetS while Apo B/A1 remained similar in both groups. We also noticed greater values of nonHDL-C and Atherogenic Index of Plasma (AIP) in obese with MetS as compared to those without MetS.

Table 2 presents the $24 \mathrm{H}$ recall results in obese patients with or without metabolic syndrome. We noticed that obese patients with MetS presented high level in Energy, Retinol, Beta-caroten, Vitamin C, and Magnesium, selenium, zinc and cooper intakes. Nevertheless, a decreasing level of PUFA, vitamin B9 and vitamin 
Moroccan Obese Patients with or without Metabolic Syndrome: Dietary Pattern and Risk of Cardiovascular Disease

Table 1: Baseline characteristics of the study population

\begin{tabular}{|c|c|c|}
\hline Parameters & $\begin{array}{c}\text { Obese without MetS } \\
(\mathbf{n = 1 2 1})\end{array}$ & $\begin{array}{c}\text { Obese with MetS } \\
(\mathbf{n = 1 2 0})\end{array}$ \\
\hline Sex-ratio & 0.29 & 0.35 \\
\hline Age (years-old) & $52.10 \pm 9.99$ & $54.45 \pm 9.33$ \\
\hline BMI (Kg/m $\left.{ }^{2}\right)$ & $33.49 \pm 3.46$ & $34.68 \pm 4.41^{*}$ \\
\hline WC & $108.18 \pm 7.90$ & $111.10 \pm 9.45^{*}$ \\
\hline sBP (mmHg) & $122.07 \pm 18.91$ & $133.13 \pm 17.55^{+}$ \\
\hline dBP (mmHg) & $73.48 \pm 9.81$ & $79.43 \pm 11.78^{+}$ \\
\hline
\end{tabular}

\section{CRP category stratification}

\begin{tabular}{|c|c|c|}
\hline CRP $<3$ mg /dL (\%) & 36.11 & 34.69 \\
\hline CRP : 3-10 mg /dL (\%) & 41.67 & 38.78 \\
\hline CRP>10 mg /dL (\%) & 22.22 & 26.53 \\
\hline Lipid parameters & & \\
\hline TC (mmol/L) & $4.98 \pm 0.83$ & $5.24 \pm 1.10^{*}$ \\
\hline HDL-C (mmol/L) & $1.43 \pm 0.27$ & $1.23 \pm 0.31^{+}$ \\
\hline LDL-C (mmol/L) & $3.01 \pm 0.78$ & $3.12 \pm 0.95^{*}$ \\
\hline TG (mmol/L) & $1.21 \pm 0.53$ & $2.01 \pm 0.94^{+}$ \\
\hline VLDL-C (mmol/L) & $0.55 \pm 0.24$ & $0.92 \pm 0.43^{+}$ \\
\hline Apo AI (mg /dL) & $158.61 \pm 36.70$ & $168.42 \pm 44.10$ \\
\hline Apo B (mg /dL) & $106.45 \pm 24.47$ & $127.01 \pm 27.28^{+}$ \\
\hline TC / HDL & $3.60 \pm 0.87$ & $4.47 \pm 1.23^{+}$ \\
\hline TG/HDL & $0.91 \pm 0.53$ & $1.80 \pm 1.16^{+}$ \\
\hline LDL/Apo B & $1.14 \pm 0.19$ & $1.80 \pm 1.16^{+}$ \\
\hline HDL/Apo A1 & $0.33 \pm 0.06$ & $0.28 \pm 0.06^{+}$ \\
\hline Apo B / AI & $0.70 \pm 0.21$ & $0.85 \pm 0.44$ \\
\hline Non HDL-C (mg /dL) & $137.34 \pm 32.21$ & $154.98 \pm 41.76^{+}$ \\
\hline AIP & $-0.10 \pm 0.21$ & $0.19 \pm 0.25^{+}$ \\
\hline
\end{tabular}

Data are mean \pm SD unless indicated otherwise.

AIP, atherogenic index of plasma; Apo, apolipoproteine; BMI, body mass index; CRP, C-reactive protein; $\mathrm{dBP}$, diastolic blood pressure; HDL-C, high density lipoprotein cholesterol; LDL-C, low density lipoprotein cholesterol; MetS, metabolic syndrome; sBP, systolic blood pressure; TC total cholesterol; TG, triglycerides; VLDL-C very low density lipoproteine cholesterol; WC waist circumference.

${ }^{*} p<0.05 ;+: p<0.0001$

E, in comparison with obese patients without MetS. Furthermore, the obese with MetS diet was more caloric but poorer in Polyunsaturated Fatty Acids (PUFA), in vitamin B9 and E.

Table 3 and 4 presents, respectively, the consumption frequencies of several food groups and consumption frequencies of several food groups according to their nutritional benefits. Both groups consume meals which macronutrient composition was similar. And the majority of patients had breakfast a lunch, a teatime and diner.

The breakfast consists of a semolina soup, coffee, milk, bread and butter or olive oil. Lunch is mainly represented by Moroccan tagines, rich in beef met, olive oil, potatoes and carrots. Bread is the essential food taken in this meal.

Otherwise, fruits and green salads represent a secondary intake. For teatime, a rich bread meal too with honey or jam, starchy Moroccan pancakes. In diner time, generally late, a meal that is same as lunch meal or based on paws, vegetable soup or semolina but every time accompanied with bread.

Table 2: $24 \mathrm{H}$ recall results in obese patients with or without MS

\begin{tabular}{|c|c|c|}
\hline Parameters & $\begin{array}{c}\text { Ob without MS } \\
(\mathbf{n = 1 2 1})\end{array}$ & $\begin{array}{c}\text { Ob with MS } \\
\text { (n=120) }\end{array}$ \\
\hline Energy (Kcal) & $2880.94 \pm 1471.33$ & $3433.39 \pm 1910.44^{*}$ \\
\hline Proteins (\%) & $27.70 \pm 34.28$ & $21.82 \pm 11.25$ \\
\hline Carbohydrates (\%) & $49.53 \pm 28.92$ & $47.08 \pm 13.18$ \\
\hline Lipids (\%) & $39.78 \pm 65.98$ & $31.06 \pm 12.01$ \\
\hline Wich SFA (\%) & $43.53 \pm 12.56$ & $45.65 \pm 15.48$ \\
\hline MUFA (\%) & $41.96 \pm 8.66$ & $41.77 \pm 12.19$ \\
\hline PUFA (\%) & $14.52 \pm 10.03$ & $12.57 \pm 10.15^{*}$ \\
\hline Cholesterol $(\mathrm{mg})$ & $319.88 \pm 483.59$ & $235.17 \pm 249.66$ \\
\hline Fibers $(\mathrm{g})$ & $20.58 \pm 11.45$ & $16.64 \pm 3.57$ \\
\hline Vitamin B9 $(\mu \mathrm{g})$ & $252.32 \pm 206.50$ & $237.10 \pm 249.66^{*}$ \\
\hline Vitamin E $(\mathrm{mg})$ & $13.34 \pm 36.06$ & $4.90 \pm 7.50^{*}$ \\
\hline Retinol $(\mu \mathrm{g})$ & $140.45 \pm 177.50$ & $194.62 \pm 212.27^{* *}$ \\
\hline Beta-Caroten $(\mu \mathrm{g})$ & $136.51 \pm 75.02$ & $179.93 \pm 253.95^{*}$ \\
\hline Vitamin C $(\mathrm{mg})$ & $59.63 \pm 64.62$ & $127.60 \pm 134.02^{*}$ \\
\hline Magnesium $(\mathrm{mg})$ & $193.71 \pm 95.01$ & $231.89 \pm 58.63^{*}$ \\
\hline Selenium $(\mu \mathrm{g})$ & $45.07 \pm 36.26$ & $59.84 \pm 40.37^{* *}$ \\
\hline Zinc $(\mathrm{mg})$ & $6.93 \pm 4.92$ & $8.59 \pm 3.49^{*}$ \\
\hline Cooper $(\mathrm{mg})$ & $0.88 \pm 0.47$ & $1.55 \pm 0.24^{*}$ \\
\hline SF & & \\
\hline Saturated & & \\
\hline
\end{tabular}

SFA: Saturated fatty acids, MUFA: Monounsaturated fatty acids, PUFA: Polyunsaturated fatty acids.

${ }^{*}: \mathrm{p}<0.05 ;{ }^{* *}: \mathrm{p}<0.01$

Table 5 represents binomial logistic regression of lipid ratios and risks of cardiovascular outcomes, regarding the type of MetS component. The ratio of TC/ HDL and AIP were the best predictors of MetS and their Ors were significantly higher in men than in women. All cardiovascular outcomes predicted risks were elevated with increased number of MetS components in men and participants with MetS. Lipid ratios were better predictors of cardiovascular risk. 


\begin{tabular}{|c|c|c|}
\hline $\begin{array}{l}\text { Mean of food intake } \\
\text { classified in several } \\
\text { categories }\end{array}$ & $\begin{array}{l}\text { Ob without MetS } \\
(n=121)\end{array}$ & $\begin{array}{l}\text { Ob with MetS } \\
\qquad(n=120)\end{array}$ \\
\hline Milk and dairy products & $\begin{array}{l}\text { More than twice } \\
\text { /day }\end{array}$ & $\begin{array}{l}\text { More than twice } \\
\text { /day }\end{array}$ \\
\hline Meats, fish and eggs & $\begin{array}{l}\text { More than once } \\
\text { /day }\end{array}$ & $\begin{array}{l}\text { More than once / } \\
\text { day }\end{array}$ \\
\hline Fruit and vegetables & $\begin{array}{c}\text { More than } 4 \text { times } \\
\text { /day }\end{array}$ & $\begin{array}{c}\text { More than } 4 \text { times } \\
\text { /day }\end{array}$ \\
\hline Fats & $\begin{array}{l}\text { More than twice } \\
\text { /day }\end{array}$ & $\begin{array}{l}\text { More than twice } \\
\text { /day }\end{array}$ \\
\hline Cereals and derivates & $\begin{array}{c}\text { More than } 3 \text { times } \\
\text { /day }\end{array}$ & $\begin{array}{c}\text { More than } 3 \text { times } \\
\text { /day }\end{array}$ \\
\hline Sugar and sweet products & $\begin{array}{c}\text { More than } 4 \text { times } \\
\text { /day }\end{array}$ & $\begin{array}{c}\text { More than } 3 \text { times } \\
\text { /day }\end{array}$ \\
\hline Beverages & $\begin{array}{l}\text { More than twice } \\
\text { /day }\end{array}$ & $\begin{array}{l}\text { More than twice } \\
\text { /day }\end{array}$ \\
\hline Spices and condiments & $\begin{array}{c}\text { More than } 6 \text { times } \\
\text { /day }\end{array}$ & $\begin{array}{c}\text { More than } 7 \text { times } \\
\text { /day }\end{array}$ \\
\hline Dried fruits and seeds & $\begin{array}{c}\text { At least once / } \\
\text { week }\end{array}$ & $\begin{array}{c}\text { At least once / } \\
\text { week }\end{array}$ \\
\hline Fast food & $\begin{array}{l}\text { At least once / } \\
\text { week }\end{array}$ & $\begin{array}{l}\text { At least once / } \\
\text { week }\end{array}$ \\
\hline
\end{tabular}

Table 4: Consumption frequencies of several food groups according to their nutritional benefits

\begin{tabular}{|c|c|c|}
\hline $\begin{array}{l}\text { Mean of intake } \\
\text { of food rich in }\end{array}$ & $\begin{array}{l}\text { Ob without MetS } \\
(n=121)\end{array}$ & $\begin{array}{l}\text { Ob with MetS } \\
(n=120)\end{array}$ \\
\hline Energy & More than 5 times /day & More than 4 times /day \\
\hline Antioxidants & Many times/ day & Many times/ day \\
\hline cholesterol & At least one /week & At last one / week \\
\hline SFA & At least one /day & At least one /day \\
\hline UFA & More than twice/day & More than twice/day \\
\hline MUFA & More than twice/day & More than twice/day \\
\hline PUFA & At least one /week & At least one /week \\
\hline Vitamins & More than 5 times /day & More than 4 times /day \\
\hline Vitamin E & More than twice/day & More than twice/day \\
\hline Vitamin C & More than twice/day & More than twice/day \\
\hline Trace elements & Many times/ day & Many times/day \\
\hline Magnesium & More than 5 times /day & More than 5 times /day \\
\hline Zinc & More than 5 times /day & More than 6 times /day \\
\hline Cooper & At least one /week & At least one /week \\
\hline Selenium & More than one/day & More than twice /day \\
\hline Bêta-caroten & More than 4 times /day & More than 4 times /day \\
\hline
\end{tabular}

Table 5: Binomial logistic regression of lipid ratios and risks of cardiovascular outcomes

\begin{tabular}{|c|c|c|c|c|c|c|c|}
\hline \multirow{2}{*}{\multicolumn{2}{|c|}{ OR(95\% CI) }} & \multirow[b]{2}{*}{$\begin{array}{c}\text { Presence vs. } \\
\text { absence of MetS }\end{array}$} & \multirow[b]{2}{*}{ Men vs. women } & \multicolumn{4}{|c|}{ Number of MS components ( vs. 1 MetS component) } \\
\hline & & & & $\begin{array}{c}2 \text { MetS } \\
\text { Components }\end{array}$ & $\begin{array}{c}3 \text { MetS } \\
\text { Components }\end{array}$ & $\begin{array}{c}4 \text { MetS } \\
\text { Components }\end{array}$ & $\begin{array}{c}5 \text { MetS } \\
\text { Components }\end{array}$ \\
\hline \multicolumn{2}{|c|}{ TC/ HDL } & $2.21(1.65-2.95)^{+}$ & $1.49(1.15-1.94)^{* *}$ & $1.47(0.91-2.38)^{+}$ & $2.04(1.35-3.09)^{* *}$ & $5.14(2.33-11.31)^{+}$ & $6.91(2.10-22.78)^{* *}$ \\
\hline \multicolumn{2}{|c|}{ LDL/ HDL } & $1.92(1.38-2.67)^{* * *}$ & $1.44(1.03-2.00)^{*}$ & $1.48(0.86-2.56)$ & $1.94(1.20-3.14)^{* *}$ & $2.94(1.41-6.16)^{* *}$ & $5.04(1.81-14.05)^{* *}$ \\
\hline \multicolumn{2}{|c|}{ Non HDL-C } & $3.57(1.72-7.41)^{+}$ & $1.51(0.70-3.29)$ & $1.02(1.00-1.04)$ & $3.36(1.15-9.83)^{*}$ & $1.03(1.00-1.06)$ & $1.08(1.00-1.18)$ \\
\hline \multicolumn{2}{|c|}{ AIP } & $2.09(1.69-2.57)^{+}$ & $1.27(0.93-1.74)^{+}$ & $1.37(1.09-1.72)^{*}$ & $1.96(1.56-2.47)^{+}$ & $2.83(1.30-6.16)^{+}$ & $2.89(0.97-8.57)^{* *}$ \\
\hline \multicolumn{2}{|c|}{ Apo B/ A1 } & $1.42(1.31-1.56)$ & $0.97(0.63-1.49)$ & $1.39(1.09-1.72)$ & $1.51(1.20-1.90)$ & $2.24(0.91-5.57)^{*}$ & $2.40(0.80-7.23)^{*}$ \\
\hline \multicolumn{2}{|c|}{ Apo B/HDL } & $2.67(1.42-5.04)^{*}$ & $1.45(0.88-2.37)$ & $1.90(0.70-5.18)$ & $2.96(1.15-7.63)^{*}$ & $2.83(2.63-3.04)^{* *}$ & $3.00(1.28-6.99)$ \\
\hline \multirow{5}{*}{ 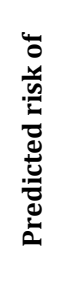 } & CHD & $1.23(1.15-1.31)^{+}$ & $1.13(1.08-1.19)^{+}$ & $1.27(1.10-1.46)^{* *}$ & $1.41(1.21-1.63)^{+}$ & $1.59(1.30-1.96)^{+}$ & $1.49(1.15-1.92)^{* *}$ \\
\hline & MI & $1.41(1.25-1.59)^{+}$ & $1.24(1.14-1.35)^{+}$ & $1.53(1.12-2.08)^{* *}$ & $1.97(1.42-2.74)^{+}$ & $2.51(1.66-3.78)^{+}$ & $2.24(1.31-3.84)^{* *}$ \\
\hline & Stroke & $1.41(1.21-1.64)^{+}$ & $1.13(1.02-1.26)^{*}$ & $3.49(1.74-7.01)^{* * *}$ & $3.79(1.91-7.52)^{* * *}$ & $4.02(2.64-6.19)^{+}$ & $4.48(1.53-13.11)^{* *}$ \\
\hline & CVD & $1.12(1.08-1.17)^{+}$ & $1.07(1.04-1.10)^{+}$ & $1.22(1.10-1.35)^{* * *}$ & $1.28(1.15-1.43)^{+}$ & $1.39(1.20-1.62)^{+}$ & $1.33(1.10-1.61)^{* *}$ \\
\hline & $\begin{array}{c}\text { CVD } \\
\text { Death }\end{array}$ & $1.27(1.13-1.42)^{+}$ & $1.19(1.09-1.29)^{+}$ & $1.71(1.06-2.77)$ & $2.22(1.31-3.76)^{* *}$ & $2.54(1.37-4.74)^{*}$ & $1.90(1.23-2.93)^{* *}$ \\
\hline \multicolumn{8}{|c|}{$\begin{array}{l}\text { TC total cholesterol; LDL, low density lipoprotein; HDL, high density lipoprotein; AIP, atherogenic index of plasma; Apo, apolipoprotein; CHD, } \\
\text { coronary heart disease; MI, myocardial infarction } \\
*: p<0.05 ;{ }^{* *}: \mathrm{p}<0,01 ;{ }^{* * *}: p<0.001 ;+: p<0.0001\end{array}$} \\
\hline
\end{tabular}




\section{Discussion}

MetS has become a public health problem, the prevalence of which is increasing worldwide $[14,15]$. Thus, the presence of the MetS is a strong predictor of future CVD and CVD death and the increase in risk begins with the presence of at least one MetS component [16]. This syndrome confers an increased risk for the development of diabetes mellitus and for cardiovascular morbidity and mortality. Mediterranean diet reflects a typical culture and lifestyle proper to the Mediterranean basin. However, Morocco has met an important nutritional transition for last years. To better become aware of these changes, we realized this study to evaluate the risk of chronic diseases associated with metabolic syndrome, dietary pattern and risks of CVD [1]. The results of our study, which took place in Casablanca, led to higher anthropometric values while the presence of metabolic syndrome in obese patients revolved a higher sBP and TG, which, in turn, was reflected by an approximate increased TG/HDL and AIP values. All of these abnormalities are responsible for elevations of risks of cardiovascular disease and coronary heart disease, morbidity and mortality.

Our results showed that Moroccan obese patients are also at high risk for CVDs, since hypo-HD Lemia and hypertriglyceridemia are higher in obese with MetS than obese without Mets, which is in agreement with other research, as well as Hong, et al. they found three metabolic syndrome component combinations that led to the highest risk of CHD: increased sBP and TGs associated with lower HDL cholesterol. And according to, Do Carmo, et al. in developed countries, low HDL-cholesterol levels, and high triglyceridaemia and hypertension were the most common MS factors $[17,18]$.

On one hand, other lipid measures have shown their own predictive value for CVD. As well as, TC, TG, HDL-C, LDL-C, Apo B, Apo AI was all significant predictors of risk: Apo A1 and Apo B were better predictors of MI and CHD than HDL-C and LDL-C levels because of their respective associations with these lipoproteins [19-23].

On the other hand, using TC/HDL and Apo B/A1 ratios, we have noticed a cholesterol imbalance between atherogenic and anti-atherogenic lipoprotein particles in obese with MetS, adults with 5 MetS features and/or hypertriglyceridemia. Consequently, those people have more cholesterol circulating in the plasma compartment, and this cholesterol is likely to be deposited in the arterial wall, provoking atherogenesis and risk of cardiovascular events $[19,20]$. Our findings were consistent with others publications where these ratios were found to be related to MetS and its components [19, 20, 24-26].

In our study, lipoproteins and apolipoproteins disturbances found in obese patients with MetS agreed with previous studies $[19,20]$. One explanation would be that excess fat disturbs lipoprotein levels: in obese persons, an increased flux of FFA from fat to the liver might stimulate production of TG-rich lipoproteins leading to a pro-inflammatory state owing to altered production of inflammatory and anti-inflammatory mediators and the recruitment of macrophages to adipose tissue [27].

We have shown that most of obese patients with MetS present CRP levels $>3 \mathrm{mg} / \mathrm{dl}$, which is in agreement total with many studies [24, 27, 28, 30, 42]. Recently, some studies suggested that CRP predicted future MetS independent of age and its five components, and that it should be added as a MetS component [28, 29, 31]. Effectively, low-grade inflammation and its association with obesity may promote IR in various tissues [32, 33]. Besides, IR leads to an increased flux of Free Fatty Acids (FFA) into various tissues because of enhanced lipolysis and reduced FFA uptake and esterification. Since FFA competes with glucose for cellular uptake and metabolism, it can further reduce insulin sensitivity, instituting a vicious cycle [20].

Diet may also be one of the most important factors determinants of MS. The current scientific evidence suggests that the adoption of healthy lifestyles, balanced diet, increased physical activity, tobacco abstention, and moderate alcohol consumption can prevent and help control chronic diseases [33]. In the INTERHEART study, daily consumption of fruits and vegetables, regular alcohol consumption, regular physical activity, and other risk factors (history of hypertension, diabetes, abdominal obesity, and psychosocial factors) were all significantly related to acute myocardial infarction [34].

The main observed nutritional anomaly in our population was an excessive energy intake, if in association with sedentarily it well sustains obesity. Furthermore, the food mostly consumed by our population is hyperglycemic, rich in high glycemic index food (bread, paws and semolina) this is clearly established in many studies [36, 37].

Several researches focused on the glycemic index for simple food or mixt meals [36,38-41]. Our patient's meals are rich in Fatty: Saturated Fatty Acid (SFA) and Monounsaturated Fatty Acid (MUFA) represented by Moroccan tagines prepared with olive oil, beef, meat potatoes and carrots). Our study showed that the obese with MetS, are very exposed to a high cardiovascular risk due to an imbalance, in the different types of fatty acids, insufficient vitamins and antioxidants intake and sedentarily life style.

\section{Conclusion}

Our data shows that CVD risk factors are highly prevalent among obese patients with Mets, because of a hypercaloric diet, an unbalanced fatty acids intakes and disturbance in lipoprotein profile, thus our population suffer from low-grade inflammation, with three to five components of MetS. All these parameters and disturbance may contribute to the development of CVD.

The burden of CVD poses a serious public health problem in the region. It is strongly associated with dietary pattern. For this reason, there is urgency for development of betters approaches to the prevention and management of the cardiovascular diseases. It is not enough to say "just treat the established risk factors." 
More importantly, an effort must be made to strike at the underlying causes of the metabolic syndrome.

Certainly, reversal of the worldwide epidemic of obesity and physical inactivity must be a high priority. But in addition, better means to treat underlying susceptibility to the metabolic syndrome to ovoid CVD also are needed. Both approaches represent a great challenge to research in the cardiovascular and metabolic syndrome fields and their association with nutrition.

\section{Ethical Approval}

The protocol of the study was approved by ethical committee.

\section{References}

1. Essiarab F, Taki H, El Malki A, Hassar M, Saile R, Ghalim N. Cardiovascular Risk Factors Prevalence in a Moroccan Population. European Journal of Scientific Research. 2011;49(4):581-589.

2. Global Burden of Disease and Injury Series, Vols. I and II, Global Health Statistics. Boston: Harvard School of Public Health 1996.

3. The World Health Report. Reducing Risks, Promoting Healthy Life. Geneva: WHO 2002.

4. Nature publishing group: cardiovascular disease prognostic/ diagnostic testing and a raft of new drug targets from genomics promise to transform cardiovascular medicine. Nature biotechnology supplement. 2000;18.

5. American Heart Association. Heart Disease and Stroke Statistics-2015 Update: a report from the American Heart Association. Circulation. 2015;131(4):e29-322. doi: 10.1161/CIR.0000000000000152

6. WHO. World health statistics. Geneva: World Health Organization;2009e.

7. National Population and Family Health Survey-2011, Main Regional Indicators, Ministry of Health, Morocco. Directorate of Planning and Financial Resources. 2011.

8. Angelova P, Boyadjiev N. A Review on the Models of Obesity and Metabolic Syndrome in Rats. Trakia journal of Sciences. 2013; 11(1): 5-12.

9. Sodjinou R,Victoire A,Fayomi B,Delisle H. Obesity and cardiometabolic risk factors in urban adults of Benin:Relationship with socio-economic status,urbanization, and lifestyle patterns.BMC Public Health. 2008;8:84. doi:10.1186/1471-2458-8-84

10. Roth JL, Mobarhan S, Clohisy M. The Metabolic Syndrome: where are we and where do we go?. Nutr Rev. 2002;60: 335-337.

11. Balkau B, Vernay M, Mhamdi L, et al. The incidence and persistence of the NCEP (National Cholesterol Education Program) metabolic syndrome. The French D.E.S.I.R. study. Diabetes Metab. 2003; 29(5): 526-532.

12. Palaniappan L, Carnethon MR, Wang Y, et al. Predictors of the incident metabolic syndrome in adults: The Insulin Resistance Atherosclerosis Study. Diabetes Care. 2004;27(3):788-793.

13. Beilby J. Definition of Metabolic Syndrome. Report of the National Heart, Lung, and Blood Institute/American Heart Association
Conference on Scientific Issues Related to Definition. Clin Biochem Rev. 2004; 25(3):195-198.

14. Grundy SM. Metabolic syndrome pandemic. Arterioscler Thromb Vasc Biol. 2008;28(4):629-636. doi: 10.1161/ATVBAHA.107.151092

15. Duncan GE, Li SM, Zhou XH. Prevalence and trends of a metabolic syndrome phenotype among us Adolescents, 1999-2000. Diabetes Care. 2004; 27: 2438-2443.

16. Arnlov J, Ingelsson E, Sundstrom J, Lind L. Impact of body mass index and the metabolic syndrome on the risk of cardiovascular disease and death in middle-aged men. Circulation. 2010;121(2): 230-236. doi: 10.1161/CIRCULATIONAHA.109.887521

17. Hong Y, Jin X, Mo J, Lin HM, Duan Y, Pu M et al. Metabolic syndrome, its preeminent clusters, incident coronary heart disease and all-cause mortality-results of prospective analysis for the atherosclerosis risk in communities' study. J Intern Med. 2007;262(1): 113-122.

18. Carmo I Do, Dos Santos O, Camolas J, Vieira J, Carreira M, Medina L, et al. Overweight and obesity in Portugal: national prevalence in 20032005. Obes Rev. 2008,9(1):11-19.

19. Walldius G, Jungner I. The apoB/apoA-I ratio: a strong, new risk factor for cardiovascular disease and a target for lipid-lowering therapy-a review of the evidence. J Intern Med. 2006;259(5) :493-519.

20. Belfki H, Ben Ali S, Bougatef S, Ben Ahmed D, Haddad N, Jmal A, et al. The Apolipoprotein $\mathrm{B} /$ Apolipoprotein $\mathrm{A} 1$ ratio in relation to metabolic syndrome and its components in a sample of the Tunisian population. Exp Mol Pathol. 2011;91(2): 622-625. doi: 10.1016/j. yexmp.2011.06.007

21. Sniderman A, Mcqueen M, Contois J, Williams K, Furberg CD. Why is non-high-density lipoprotein cholesterol a better marker of the risk of vascular disease than low-density lipoprotein cholesterol? J Clin Lipidol. 2010; 4(3):152-155. doi: 10.1016/j.jacl.2010.03.005

22. Walldius $\mathrm{G}$, Jungner $\mathrm{I}$. Is there a better marker of cardiovascular risk than LDL cholesterol? Apolipoproteins B and A-I-new risk factors and targets for therapy. Nutr Metab Cardiovasc Dis. 2007;17(8):565-571.

23. Contois JH, Warnick GR, Sniderman AD. Reliability of low-density lipoprotein cholesterol, non-high-density lipoprotein cholesterol and apolipoprotein B measurement. 2011; 5(4):264-272. doi: 10.1016/j. jacl.2011.05.004

24. Belfki H, Ben Ali S, Bougatef S, Ben Ahmed D, Haddad N, Jmal A, et al. Relationship of C-reactive protein with components of the metabolic syndrome in a Tunisian population. Eur J Intern Med. 2012;23(1) :5-9. doi: 10.1016/j.ejim.2011.10.011

25. Onat A, Can G, Hergenc G, Yazıcı M, Karabulut A, Albayrak S. Serum apolipoprotein B predicts dyslipidemia, metabolic syndrome and, in women, hypertension and diabetes, independent of markers of central obesity and inflammation. Int J Obes (Lond). 2007;31(7):1119-1125.

26.Zhong L, Li Q, Jiang Y, Cheng D, Liu Z, Wang B, et al. The ApoB/ApoA1 ratio is associated with metabolic syndrome and its components in a Chinese population. Inflammation. 2010; 33(6):353-358.

27. Lusis AJ, Attie AD, Reue K. Metabolic syndrome: from epidemiology to systems biology. Nat Rev Genet. 2008; 9(11):819-830. 
28. Shuumarjav U, Kotani K, Taniguchi N. Association between serum C-Reactive Protein and metabolic syndrome in Mongolian patients in comparison to Japanese patients. Ethn Dis. 2011; 21(1):74-78.

29. Devaraj S, Singh U, Jialal I. Human C-reactive protein and the metabolic syndrome. Curr Opin Lipidol. 2009; 20(3):182-189. doi: 10.1097/ MOL.0b013e32832ac03e

30. Onat A, Can G, Hergenc G. Serum C-reactive protein is an independent risk factor predicting cardiometabolic risk. Metabolism. 2008; 57(2) 207-214.

31. Holvoet P, De Keyzer D, Jacobs DR Jr. Oxidized LDL and the metabolic syndrome. Future Lipidol. 2008; 3(6):637-649.

32. Wildman RP, Kaplan R, Manson JE, Rajkovic A, Connelly SA, Mackey $\mathrm{RH}$, et al. Body size phenotypes and inflammation in the Women's Health Initiative Observational Study. Obesity. 2011;19(7):1482-1491. doi: 10.1038/oby.2010.332

33. Onat A, Hergenc G. Low-grade inflammation, and dysfunction of high-density lipoprotein and its apolipoproteins as a major driver of cardiometabolic risk. Metabolism. 2011; 60(4): 499-512. doi: 10.1016/j.metabol.2010.04.018

34. Kim S, Popkin BM, Siega-Riz AM, Haines P, Arab L. A cross-national comparison of lifestyle between China and the United States, using a comprehensive cross-national measurement tool of the healthfulness of lifestyles: the Lifestyle Index. Prev Med. 2004;38(2):160-171.
35. Yusuf S, Hawken S, Ounpuu S, Dans T, Avezum A, Lanas F, et al. Effect of potentially modifiable risk factors associated with myocardial infarction in 52 countries (the INTERHEART study): case-control study. Lancet. 2004;364(9438): 937-952.

36. Chien KL, Hsu HC, Su TC, Chen MF, Lee YT, Hu FB. Apolipoprotein B and non-high density lipoprotein cholesterol and the risk of coronary heart disease in Chinese. J Lipid Res. 2007;48(11): 2499-2505.

37. Halimi S, Ressel M, Siaud C, Debaty I. Aspects qualitatifs des apports glucidiques: index glycémique des aliments et fibres alimentaires. Médecine Des maladies Métaboliques. 2007;1(3):21-25.

38. Ben Mami F, Dakhli S, Berriche 0 , et al. Le régime alimentaire du diabétique Tunisien: Vécu et recommandations. Revue maghrébine d'Endocrinologie-Diabète et Reproduction 2005 ; 10 :201-205.

39. Coulibaly A, Turgeon O’Brien H, Galibois I. Croyances Beliefs and food practices of type 2 diabetic patients in Bamako (Mali). Cah Nutr Diét. $2009 ; 44: 136-142$.

40. Al-Adsani AM, Moussa MA, Al-Jasem LI, Abdella NA, Al-Hamad NM. The level and determinants of diabetes knowledge in Kuwaiti adults with type 2 diabetes. Diabètes Metab. $2009 ; 35(2)$ :121-128. doi: 10.1016/j.diabet.2008.09.005

41. Bongard V, Ruidavets JB. Comportement alimentaire des sujets diabétiques ou atteints de Syndrome métabolique en France (données issues d'un échantillon d'hommes âgés de 45 à 64 ans). Médecine des maladies Métaboliques. 2007; 3(1):37-40. 